Original Research Article

\title{
Perception and practice of self-medication amongst second year medical students in a tertiary care teaching hospital
}

\author{
Amullya C. Pednekar*, Padma N. Bhandare, Shantadurga S. Kerkar
}

Department of Pharmacology,

Goa Medical College and Hospital, Bambolim, Goa, India

Received: 28 April 2019

Accepted: 30 May 2019

*Correspondence to:

Dr. Amullya Pednekar,

Email: amullya32@gmail.com

Copyright: (C) the author(s), publisher and licensee Medip Academy. This is an openaccess article distributed under the terms of the Creative Commons Attribution NonCommercial License, which permits unrestricted noncommercial use, distribution, and reproduction in any medium, provided the original work is properly cited.

\begin{abstract}
Background: Management of medical ailments requires sound knowledge of diseases and drugs. Medical students are more likely to practice self-medication due to easy access to information. Inappropriate and inadequate treatment can lead to morbidity and mortality. Thus, the current study was carried out to understand the perception and practice of self-medication in medical students so that habit of ethical practice can be inculcated in them.

Methods: A self-developed and prevalidated questionnaire was distributed amongst 145 students of second MBBS after approval from Institutional ethics Committee. Data was collected; analysed using MS Excel and the results were expressed as counts and percentages.

Results: In this study authors noted 136 (93.79\%) out of the 145 students practised self-medication. The commonest reason being effectiveness of medications for similar conditions in the past $92(69.17 \%) .111(81.61 \%)$ students reported fever as the most common indication. Analgesics/anti-pyretics 117 $(86.02 \%)$ were the most frequently used drug groups. Majority $87(63.97 \%)$ obtained information from friends and relatives. Adverse effects of selfmedication were noted in 20 (14.70\%).

Conclusions: This study indicates higher prevalence of self-medication in medical students of Goa. Students can be sensitised and made aware about possible adverse effects and drug interactions with self-medication and how simple looking illness may take an ugly turn. Students being future doctors will continue this chain of spread of awareness of self-medication. Easy access to healthcare can also solve these problems.
\end{abstract}

Keywords: Awareness, Medical students, Perception, Practice, Questionnaire, Self-medication

\section{INTRODUCTION}

Self-medication is defined as self-administering drugs which include herbal and traditional products to treat selfdiagnosed ailments without a physician's consultation or valid prescription for the same. Self-medication forms one of the elements of self-care. ${ }^{1}$

WHO endorses practice of responsible self-medication in some conditions that are self-recognisable and for some chronic or recurrent condition (following initial medical diagnosis) using medicines with proven safety, quality and efficacy. The drugs available and approved for this purpose without a physician's prescription are called as over the counter (OTC) drugs. ${ }^{2}$

OTC drugs are the only drugs, which can be sold without a need of a valid prescription. ${ }^{3}$ These products should be accompanied with information which explains how to use the medicine, effects and likely adverse effects, monitoring of the effects, dosage schedule, precautions, 
possible drug or food interactions and when to seek advice of a health care professional. ${ }^{4}$

Responsible self-medication provides quick and inexpensive access to treatment, thereby reducing the burden on healthcare resources of a country like India which has limited number of health professionals. However because of improper regulation and easy availability of prescription as well as non-prescription drugs, immoral self-medication has become a rampant practice in India. ${ }^{5}$ Such inappropriate self-medication can result in wrong diagnosis which may lead to delayed treatment and failure of therapy, adverse drug reactions, dangerous drug interactions, incorrect manner and dose of administration, prolonged suffering, and risk of development of bacterial resistance and drug dependence. ${ }^{6}$

Effective treatment of any ailment requires sound knowledge of disease as well as the drugs. Even though MBBS students have wealth of information at their helm to diagnose themselves and self-medicate, they lack in expertise. As future health care providers and prescribers, understanding practice of self-medication in these students is of paramount importance so that habits of ethical practice are inculcated in their budding years. Although many studies have been previously done on this subject, yet none have been done in Goa. Keeping this in mind, the current study was carried out in Goa Medical College to assess the perception and practice of self-medication amongst second year medical students.

\section{METHODS}

The study was a prospective, cross-sectional, questionnaire-based study which was conducted in second MBBS students of Goa Medical College and Hospital, Bambolim, Goa, India. Prior approval from Institutional Ethics Committee was taken. The study was conducted over a period of one month from September 2018 to October 2018.

The study aims and procedures were explained to the second MBBS students and all those willing to participate and provide written informed consent were included in the study. Those unwilling or those with incompletely filled questionnaire were excluded from the study.

Self-developed and prevalidated questionnaire assessing the practice of self-medication was provided to 145 enrolled participants and feedback was obtained. Questionnaire consisted of 2 sections: section A and B. Section A included questions regarding demographic details of the participants. Section B consisted of 14 questions assessing the perception and practice of selfmedication amongst them.

All the data collected was analysed using Microsoft Excel 2016 and results expressed as counts and percentages. Descriptive analysis was performed by SPSS version 20 .

\section{RESULTS}

Total 145 students participated in the study voluntarily, of which $57(39.31 \%)$ were males and 88 (60.69\%) were females. Mean age of participating students was 19.98 years.

Out of the 145 students $136(93.79 \%)$ had used medication for self-diagnosed ailments at some point in the past. The most common reasons given for self-medicating were effectiveness of medicines for similar conditions in the past $(92(69.17 \%))$ and that minor conditions do not require a doctor's visit (63(47.36\%)) (Figure 1).

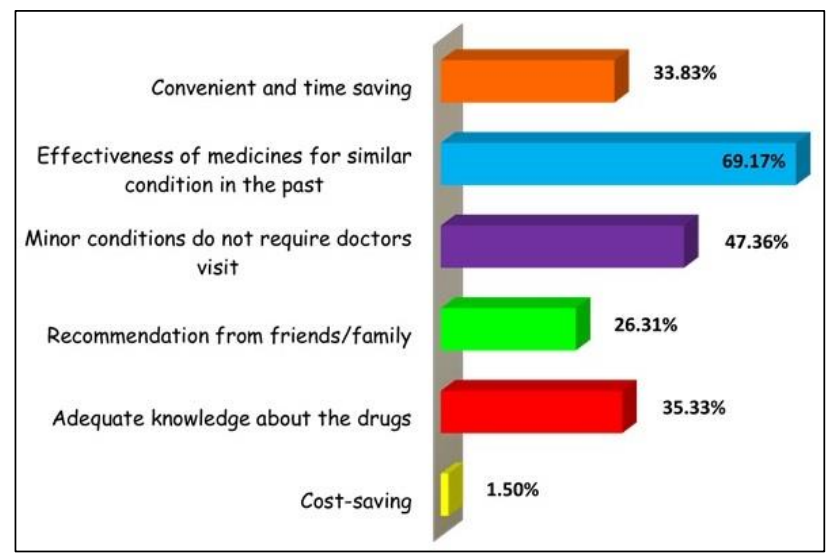

Figure 1: Reasons for opting to self-medicate.

Table 1: Common symptoms for which medications used.

\begin{tabular}{|lc|}
\hline Symptoms & Number (\%) \\
\hline Fever & $111(81.61 \%)$ \\
\hline Respiratory symptoms (cough/ sore throat/ running nose /respiratory tract infection) & $94(69.11 \%)$ \\
\hline Aches and pains (headache / body ache/abdominal pain. dysmenorrhoea) & $89(65.44 \%)$ \\
\hline Gastric symptoms (diarrhoea/ constipation / gastritis/ indigestion) & $78(57.35 \%)$ \\
\hline Skin infections and allergies & $23(16.91 \%)$ \\
\hline Ocular and ear symptoms & $14(10.29 \%)$ \\
\hline Nutritional deficiencies & $21(15.44 \%)$ \\
\hline Depression /Anxiety/ Insomnia & $1(0.73 \%)$ \\
\hline
\end{tabular}


Fever $(111(81.61 \%))$, respiratory symptoms like cold, cough, sore throat, runny nose $(94(69.11 \%))$, aches and pains like headache, bodyache, abdominal pain (89 $(65.44 \%))$ were the most common symptoms for which medications were taken (Table 1).

Analgesics and antipyretics $(117(86.02 \%)$ ) and cough syrups $(96(70.58 \%))$ were the most common selfmedicated drugs. An interesting finding in our study was that significantly high number of students $(39(28.67 \%))$ had used antibiotics without a valid prescription from the doctor (Table 2).

Table 2: Common groups of drugs used for self-medication.

\begin{tabular}{|ll|}
\hline Type of drugs used & Number (\%) \\
\hline Analgesics / Antipyretics & $117(86.02 \%)$ \\
\hline Cough syrups & $96(70.58 \%)$ \\
\hline Anti-diarrhoeal/ Laxatives & $51(37.50 \%)$ \\
\hline Antacids & $43(31.61 \%)$ \\
\hline Antimicrobials & $39(28.67 \%)$ \\
\hline Nasal decongestants & $39(28.67 \%)$ \\
\hline Multivitamins & $36(26.47 \%)$ \\
\hline Anti-allergics & $29(21.32 \%)$ \\
\hline Eye and ear drops & $19(13.97 \%)$ \\
\hline Sedatives & $3(2.20 \%)$ \\
\hline Anti- spasmodic & $2(1.47 \%)$ \\
\hline Steroids & $1(0.73 \%)$ \\
\hline
\end{tabular}

Majority of students (116(85.29\%)) procured the drugs directly from the pharmacy with others acquiring them from their own homes $(95(69.85 \%))$, friends/relatives $(23(16.91 \%))$ and online stores $(3(2.20 \%))$ (Figure 2). The information about the drugs used by them were obtained from friends/relatives $(63.97 \%)$, classroom and literature (45.59\%), pharmacist (43.38\%) and internet (25.73\%).

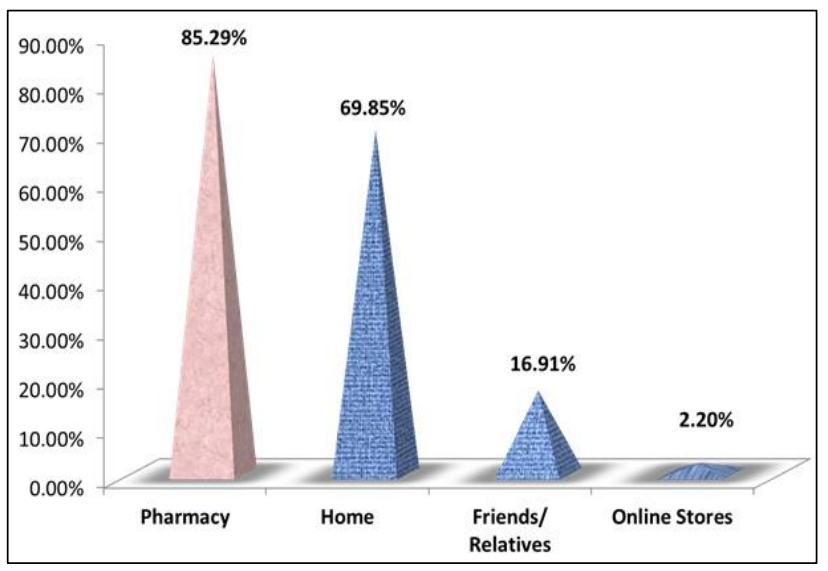

Figure 2: Sources of procuring drugs.

Only 42 students (30.88\%) agreed to have always completed the course of the medication taken, whereas the rest of them occasionally or never completed the course of medication. $36(26.47 \%)$ students admitted having increased or decreased the dose of medication in view of worsening or improving condition respectively. 23 students $(16.91 \%)$ encountered adverse effects with the drugs used of which almost half (12(52.17\%)) of them stopped the medication and consulted the doctor whereas others continued the drugs in lower dose $(7(30.44 \%))$ or same dose (4(17.39\%)) (Figure 3).

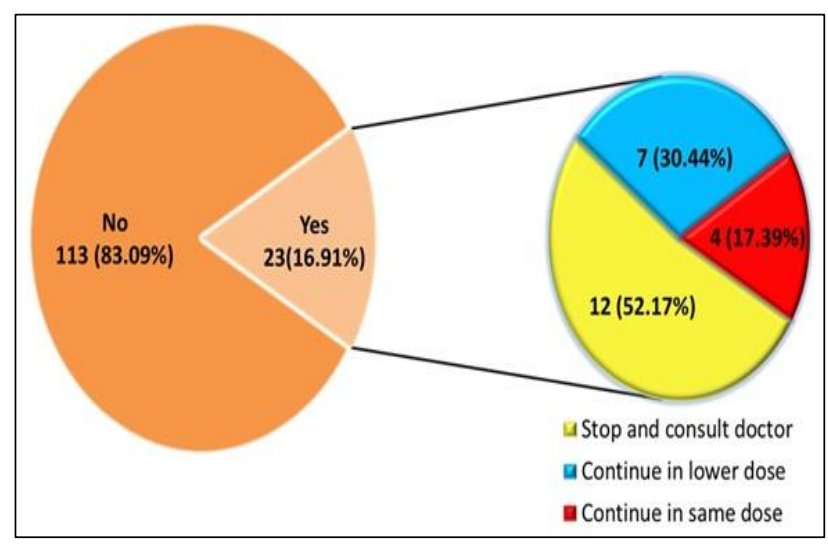

Figure 3: Adverse effects noted and next step taken.

Majority of the students (127(93.38\%)) always checked the expiry date of the drug before consuming it whereas $90(66.17 \%)$ of them agreeing to have always read the package inserts/labels. $59.56 \%$ (81) of the students felt that self-medication is not entirely safe, however $90.29 \%$ (121) of the students felt it was an acceptable practice and a little more than half of them $(69(53.08 \%))$ even saying that they will suggest self-medication to family/friends. Majority of the students $(128(94.12 \%))$ agreed that knowledge acquired by them till now has made them more cautious while using medication.

\section{DISCUSSION}

The present study was conducted with an aim to explore perception and practice of self-medication among 2nd MBBS students as they are more prone to use medicines with easy access to information as well as drugs.

In present study authors found that prevalence of selfmedication in the students was $93.79 \%$ which was higher when compared to studies conducted in India, Egypt, Saudi Arabia and Bangladesh.,3,7-10,11 This higher prevalence maybe attributed to easy access to information as well as easy availability of drugs at medical stores and at one's own home.

Effectiveness of the medicine for similar conditions in the past $(69.17 \%)$ was the main reason for self-medicating in present study while Patil SB et al, and Kasulkar A et al, noted it for mild nature of illness. ${ }^{10,12}$ Fever $(81.61 \%)$ was the main symptom while analgesic/antipyretic most commonly used drug group in our study which was in accordance with Kasulkar A et al. ${ }^{10}$ Adverse effects were noted by $16.91 \%$ of the students in our study which was higher when compared to Jagadeesh $\mathrm{K}$ et al, and Patil SB 
et al. ${ }^{2,12}$ These findings are important as many a times a symptom may just be tip of an iceberg and treating them just based on effectiveness of drugs in the past is not recommended as it may lead to adverse events, drug resistance and incomplete treatment. Thus there is a growing need to make students aware of such harmful effects of self-medication.

In present study, pharmacy $(85.29 \%)$ formed a major source of procuring drugs. Similar findings were noticed in studies from Bhopal and Nagpur. ${ }^{7,10}$ Over the counter (OTC) supply of medicines contribute considerably to self-medication. Periodic checks on pharmacies are needed as pharmacists are uniquely placed at the helm of drug distribution and dispensing. Advertisements of drugs through media and promotional literatures must be vigilantly monitored.

The information for the use of drugs to self-medicate in present study, was obtained by students from friends and relatives $(63.97 \%)$ whereas studies in Karnataka and Punjab found pharmacists $(65 \%)$ and old prescriptions $(42.4 \%)$ respectively, to be the chief source of information about the drugs ${ }^{8,13} 93.28 \%$ students in present study always made sure to check expiry date before using a drug which was similar to a study done in Nepal. ${ }^{14}$ Checking for expiry is a good practice to ensure highest efficacy and safety from the drugs that we consume.

Package inserts/labels were read by $66.17 \%$ of students which was similar to a study conducted in Bangladesh. ${ }^{3}$ Reading package labels and inserts ensures patient is aware of the latest instructions and dosage patterns of the medicine to be consumed.

Only $30.88 \%$ students always completed the course of medication taken which is of great concern. Such incomplete and inadequate treatment may lead to drug resistance and recurrence.

Limitation of this study was that we included only 145 students; but more such studies involving large number of medical students as well as students from the other streams and centres are needed. The study cannot rule out mutual influence in between students while filling the questionnaire. The study also did not differentiate between OTC drugs and prescription drugs which may have created some confusion amongst students.

\section{CONCLUSION}

Present study was first of its kind study on self-medication done in medical students in Goa. The prevalence of selfmedication amongst $2^{\text {nd }}$ MBBS students was found to be very high. The students need to be sensitized about the hazardous effects of self-medication and made aware that a simple looking illness may take an ugly turn. As these students are our future doctors they will carry the flame of awareness forwards.
At the pharmacy level, stringent steps need to be taken to curb the sale of prescription drugs as over the counter products. Also health care facilities need to be made easily accessible and cost effective. Public awareness via the media like television, newspaper, social media etc. can help to curb unethical practice of self-medication.

\section{ACKNOWLEDGEMENTS}

Authors would like to thank to express their gratitude to all the students who consented to participate in the study and gave their valuable time to answer the questionnaire that helped to complete the study.

Funding: No funding sources Conflict of interest: None declared

Ethical approval: The study was approved by the Institutional Ethics Committee

\section{REFERENCES}

1. Albusalih F, Naqvi A, Ahmad R, Ahmad N. Prevalence of self-medication among students of pharmacy and medicine colleges of a public sector university in Dammam city, Saudi Arabia. Pharmacy. 2017;5(3):51

2. Jagadeesh K, Chidananda KN, Revankar SP, Prasad NS. Study on self-medication among 2 nd year medical students. Int J Basic Clin Pharmacol. 2015;4:164-7.

3. Seam M, Bhatta R, Saha B, Das A, Hossain M, Uddin $\mathrm{S}$ et al. Assessing the perceptions and practice of selfmedication among bangladeshi undergraduate pharmacy students. Pharmacy. 2018;6(1):6.

4. The Role of the Pharmacist in Self-Care and SelfMedication: Available at: http://apps.who.int/medicinedocs/en/d/Jwhozip32e/3. 3.html\#Jwhozip32e.3.3. Accessed 27 April 2019.

5. Kumar R, Goyal A, Padhy BM, Gupta YK. Selfmedication practice and factors influencing it among medical and paramedical students in India: a twoperiod comparative cross-sectional study. J Nat Sc Biol Med. 2016;7(2):143-8.

6. Ruiz ME. Risks of self-medication practices. Curr Drug Saf. 2010;5(4):315-23.

7. Sankdia RK, Agrawal M, Rekha PB, Kothari N. A questionnaire based study regarding the knowledge, attitude and practice of self-medication among second year undergraduate medical students. Int J Pharmacol Clin Sci.2017;6(1):01-05.

8. Bagewadi HG, Deodurg PM, Patil BV, Zahid SH. Perceptions and practices of self-medication among undergraduate medical students at Gulbarga Institute of Medical Sciences, Kalaburagi. Int J Basic Clin Pharmacol. 2018;7:63-7.

9. Sontakke S, Bajait C, Pimpalkhute S, Jaiswal K, Jaiswal S. Comparative study of evaluation of selfmedication practices in first and third year medical students. Int J Bio Med Res. 2011;2(2):561-64. 
10. Kasulkar A, Gupta M. Self medication practices among medical students of a private institute. Indian $\mathbf{J}$ Pharm Sci. 2015;77(2):178-82.

11. El-Ezz NFA, Ez-Elarab HS. Knowledge, attitude and practice of medical students towards self-medication at Ain Shams University, Egypt. J Prev Med Hyg. 2011;52:196-200.

12. Patil SB, Vardhamane SH, Patil BV, Santoshkumar J, Binjawadgi AS, Kanaki AR. Self-medication practice and perceptions among undergraduate medical students: a cross-sectional study. J Clin Diagn Res. 2014 Dec;8(12):HC20-3.

13. Bhatia M, Ripudaman S, Akashdeep S, BL B. Knowledge, attitude and practice of self medication among undergraduate medical students of Punjab. The J Med Res. 2017;3(3):151-4.

14. Sharma D, Gurung D, Kafle R, Singh S. Knowledge and practice on over-the-counter drugs among adults of age group 20 and above residing in Chapapani, Pokhara, Kaski, Nepal. Int J Sci Rep. 2017;3(3):79-86.

Cite this article as: Pednekar AC, Bhandare PN, Kerkar SS. Perception and practice of selfmedication amongst second year medical students in a tertiary care teaching hospital. Int J Basic Clin Pharmacol 2019;8:1610-4. 